\title{
ONE-STAGE VERSUS TWO-STAGE PROTOCOL IN MANAGEMENT OF INFECTED NONUNITED FRACTURE FEMUR; RANDOMIZED CONTROLLED TRIAL
}

\author{
Khaled M Emara*, Ramy A Diab*, Mohamed A El-Kersh*, Ayman F Mounir*, and \\ Ahmed M Badreldin**
}

* Orthopaedic Surgery
Department, Faculty of Medicine
- Ain Shams University
** Orthopaedic Surgery
department Embaba General
Hospital, Ministry of Health,
Cairo, Egypt.
Corresponding author
Ahmed M Badreldin
Mobile: (+2) 01060520018
E.mail:
drbadoora@ gmail.com

Received: 23/6/2021

Accepted: 19/7/2021

Online ISSN: 2735-3540

\begin{abstract}
:
Background: The rate of complex fracture non-unions is increased. Infected non-united fractures need more search for the best method of management.
\end{abstract}

Aim of the work: to compare one-stage protocol (external fixation) and two-stage protocol (debridement, removal of metal, and internal fixation after eradication of infection) in cases of infected non-united fracture femur.

Patients and methods: The study was conducted at the Orthopaedic Surgery department Ain Shams University Hospital and Embaba General Hospital from Sep-2017 to Sep-2020 on 20 patients grouped into: one-stage protocol 10 cases and two-stage protocol 10 cases.

Results: There was no significant difference between groups concerning age and gender. The healing time was 8.6 2.5 and $8.4 \pm 1.7$ months for the one-stage group \& the two-stage group, respectively. The range of motion of knee six months after healing was significantly $(p$-value $=0.025)$ better in the two-stage group. The median $(I Q R)$ range of movement was 100 (50) and 110 (30) degrees for the onestage group \& the two-stage group, respectively. The most frequent complication in the one-stage group was PTI (100\% of cases); however, in the two-stage group, it was the recurrence of infection $(30 \%)$, $(p$-value $=0.01)$.

Conclusion: The two-stage strategy had a better range of motion of knee, less period of immobilization, better psychological status six months after healing but had a higher risk of recurrence of infection.

Keywords: Infected Non-United Fracture Femur; One-Stage Protocol; Two-Stage Protocol

\section{INTRODUCTION:}

The incidence of complex fracture nonunions is increased due to increased road traffic accidents and increased open fractures. These patients are usually operated upon several times for stabilization and to eradicate the infection ${ }^{[1]}$. Treatment of infected non-united fractures is technically demanding, prolonged, and needs a team. The presence of implants promotes the development of infection. Bone gap and active infection are the crucial factors relating to treatment and prognosis as it demands methods that offer infection control and provide stability to promote union ${ }^{[2]}$.

Due to the high incidence of infected non united fractures, more methods of management are mandatory. There are two schools of thought in treating infected non-united fractures, the 'union-first' strategy, and the 'infection-elimination first' strategy. The first 
strategy aims to achieve union first and then deal with the infection. The second strategy aims to eliminate infection as the first and significant objective and bone union as the next [3\&4].

Ilizarov technique has been utilized to manage septic non-union of long bones. It uses compression, distraction, bone lengthening, and deformity correction ${ }^{[5]}$. Also, femoral nonunions can be treated successfully by internal fixation. However, a septic non-union of the fracture femur can prove a complex problem compounded by bone loss, deformity, or failure of previous internal fixation [6]. After intramedullary nailing, the treatment includes the removal of metalwork, radical bony debridement, deep tissue sampling, and elimination of dead space, and insertion of local antibiotics delivery systems, followed by the Ilizarov external fixator application ${ }^{[6]}$.

Successful treatment of infected nonunited fractures in one stage is very unlikely due to local and host factors that are favorable to infection like comminution, bone loss, presence of a metallic implant, and diabetes. These factors are in favor of a two-stage protocol with the initial stage, including removing all implants, aggressive debridement and irrigation, temporary stabilization of the fracture, and bacterial-specific antibiotic treatment. The second stage includes revision, open reduction, and internal fixation ${ }^{[7]}$. The purpose of this study was to compare the two strategies, the one-stage protocol versus the two-stage protocol, in terms of efficacy, safety, and outcomes.

\section{AIM OF THE WORK:}

The aim of the study was to compare the results of one-stage management (external fixation technique) and two-stage management (debridement, removal of metal, and another stage of internal fixation after eradication of infection) in the management of cases of infected non-united fracture femur.

\section{PATIENTS AND METHODS:}

This parallel-randomized controlled, multicenter pilot study was conducted at the Orthopaedic Surgery department Ain Shams University Hospital and Embaba General Hospital with 20 patients to compare between the results of a protocol of one-stage management (external fixation technique) and two-stage management (debridement, removal of metal, and another stage of internal fixation after eradication of infection) in the management of cases of the infected non-united fractured femur during the period from September 2017 to September 2020. The ethical review committee approved the study. The purpose of this study was clearly explained to all patients before their enrollment.

We invited all patients aged 18 years or more who came to the hospitals with an infected non-united femur fracture. For inclusion in the study, all of the following criteria were to be fulfilled: age 18 years or more, patients with infected non united or delayed union femoral fractures fixed either by plate or by intramedullary nail were included in the present study. Exclusion criteria included patients with a bony gap of more than $5 \mathrm{~cm}$ or patients with a history of vascular insufficiency or thrombosis of the affected limb.

For allocation of the participants, a computer-generated list of random numbers was used. Allocation was done using the sealed envelope technique. The study was non-blinded study. Before randomization, all patients in both groups have a preoperative radiological assessment by plain x-rays AP and lateral view of affected femur, and preoperative laboratory assessment in the form of erythrocyte sedimentation rate (ESR) creactive protein (CRP) \& complete blood count (CBC). After randomization, all patients of the one-stage protocol group were managed by removal of the infected implant, debridement of the fracture site, and application of Ilizarov or LRS at the same 
session. Debridement of the fracture site was made through a lateral approach with thorough excision of all infected tissues and necrotic bone. Use of autogenous cancellous bone graft was done in patients with bone defects less than two cms. If the bone defect is from 2-5 $\mathrm{cm}$, acute shortening was made, then lengthening after healing of infection and achievement of complete union. Fixation with Ilizarov frame was done with acute shortening and compression at the fracture site in patients with bone defects of two $\mathrm{cm}$ or more.

All patients of the two-stage protocol group were managed on two sessions: First is the removal of the implant, aggressive debridement of the wound at the fracture site through lateral approach followed by antibiotic therapy until ESR and CRP become normal. Then, CRP was done every two weeks between the two stages and followed by another session for internal fixation of fracture by intramedullary nail or plate after six weeks with the use of autogenous cancellous bone graft in patients with bone defects less than two $\mathrm{cms}$.

Postoperatively, both groups have had culture and sensitivity of discharge intraoperatively followed by antibiotic therapy according to culture results. Patients had followed by ESR and CRP for eradication of infection, $\mathrm{x}$-rays for union, and clinical examination for complications and functional outcome. That was done every two weeks. Follow-up and assessment of the patients were done as regards: cure of infection, duration till union, the occurrence of complications such as knee stiffness, pin tract infection, or limb length discrepancy. Plain X-rays were done until detection of radiologically evident full union, early weight-bearing, and knee range of motion were encouraged.

The sampling technique used in this study was convenient sampling of 20 cases (10 per group). The primary outcome measure was the difference in the range of movement of knee in both groups. The secondary outcomes were healing time, recurrence of infection and rate of postoperative complications. All statistical tests were made using a significance level of 95\%. A p-value < 0.05 was considered statistically significant. SPSS software (Statistical Package for the Social Sciences, version 24.0, SSPS Inc., Chicago, IL, USA) was used. Data was presented as mean and standard deviation (mean \pm SD) for quantitative parametric data, and Median and Interquartile range (IQR) for quantitative non-parametric data. Frequency and percentage were used for presenting qualitative data. Comparisons between groups were made using Chi-square test or fisher exact test for categorical variable and the independent t-test or Mann Whitney test for the continuous variables.

\section{RESULTS:}

Twenty patients who met the inclusion criteria were randomized into two groups: One-stage protocol group 10 cases, and twostage protocol group 10 cases.

There was no significant difference between the two study groups as regards to age $(\mathrm{p}$-value $=0.783)$. The mean age was $32.3 \pm 9.1$ and $33.8 \pm 14.4$ years for the onestage group \& the two-stage group, respectively. Also, there was no significant difference between the two study groups as regard gender ( $\mathrm{p}$-value $=0.606)$. Males constituted $80 \%$ \& $70 \%$ of cases in the onestage group \& the two-stage group, respectively. Also, there was no significant difference between the two study groups with regard to the duration of septic nonunion ( $\mathrm{p}$-value $=0.845)$. The mean duration was $23.4 \pm 10.0$ and $22.9 \pm 9.7$ months for the one-stage group \& the two-stage group, respectively. The following figure illustrates the duration for both groups. 


\section{Khaled M Emara, et al.,}

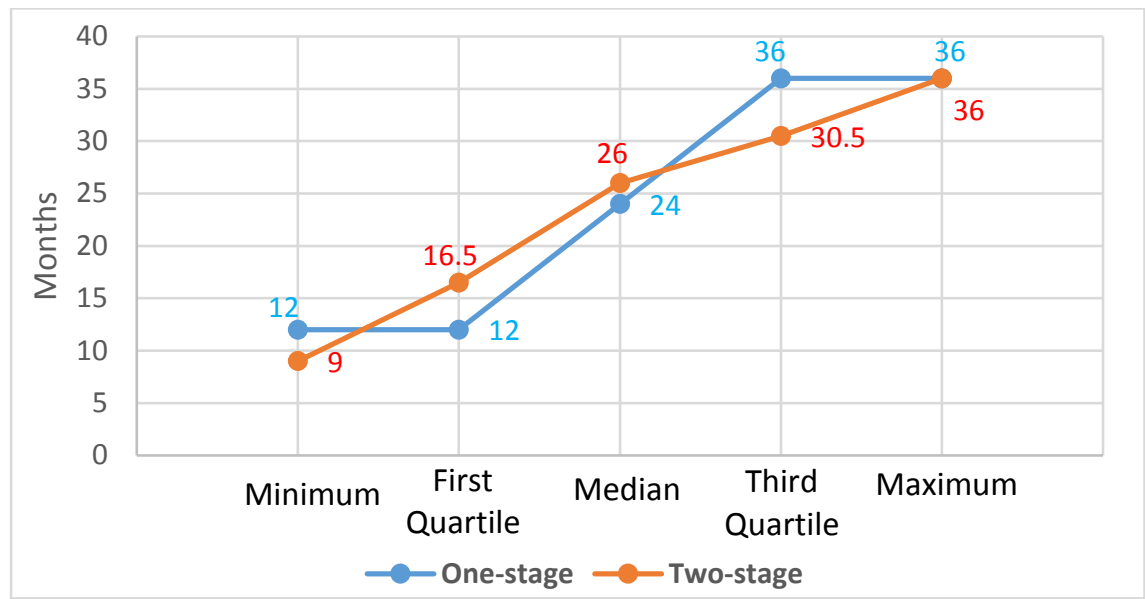

Diagram 1: Duration of septic non-union

Both groups were comparable with regard the level of septic non-union ( $p$-value $=0.09$ ). Most cases in the one-stage group had distal fracture whereas $50 \%$ of the twostage had shaft fracture.

Table 1: Baseline characteristics

\begin{tabular}{|c|c|c|c|}
\hline & One-stage & Two-stage & $\mathrm{p}$-value \\
\hline Age & $32.3 \pm 9.1$ & $33.8 \pm 14.4$ & 0.783 \\
\hline Duration of non-union & $23.4 \pm 10.0$ & $22.9 \pm 9.7$ & 0.845 \\
\hline Gender: Male : Female & $8(80.0): 2(20.0)$ & $7(70.0): 3(30.0)$ & 0.606 \\
\hline Level: & $60(60.0)$ & $2(20.0)$ & 0.09 \\
\hline Proximal & $1(10.0)$ & $3(30.0)$ & \\
\hline Shaft & $3(30.0)$ & $5(50.0)$ & \\
\hline
\end{tabular}

There is a highly significant difference between both groups as regards the method of previous fixation (p-value 0.001). Fixation was made by a nail in $30 \%$ and $70 \%$ and by a plate in $70 \%$ and $30 \%$ of both the one-stage and the two-stage group, respectively. However, there is a highly significant difference between both groups as regards the method of final fixation (p-value 0.001). Final fixation was made by Ilizarov in $100 \%$ of the one-stage. In the twostage group, the final fixation was made by a nail in $20 \%$ of cases and by a plate in $80 \%$, as shown in Table 2.

Table 2: Method of previous and final fixation.

\begin{tabular}{|c|c|c|c|}
\hline & One-stage & Two-stage & \\
\hline & $\mathrm{N}=10$ & $\mathrm{~N}=10$ & p-value \\
\hline \multicolumn{4}{|l|}{ Previous fixation } \\
\hline Nail & $3(30.0)$ & 7 (70.0) & 0.001 \\
\hline Plate & $7(70.0)$ & $3(30.0)$ & \\
\hline \multicolumn{4}{|l|}{ Final fixation } \\
\hline Ilizarov & $10(100.0)$ & $0(0.0)$ & 0.001 \\
\hline Nail & $0(0.0)$ & $2(20.0)$ & \\
\hline Plate & $0(0.0)$ & $8(80.0)$ & \\
\hline
\end{tabular}


The mean healing time was $8.6 \pm 2.5$ and $8.4 \pm 1.7$ months for the one-stage group \& the two-stage group, respectively ( $\mathrm{p}$-value $=$ 0.945). However, there was a significant difference between the two study groups as regards to the range of movement of the knee six months after healing ( $\mathrm{p}$-value $=$ 0.025). The median (IQR) range of movement was 100 (50) and 110 (30) degrees for the one-stage group \& the twostage group, respectively, Table 3 . The change in ROM before and after management was significant between the two study groups ( $\mathrm{p}$-value $=0.001$ ). The ROM was the same in $90 \%$ \& $30 \%$ for the one-stage group \& the two-stage group, respectively, Table 3 .

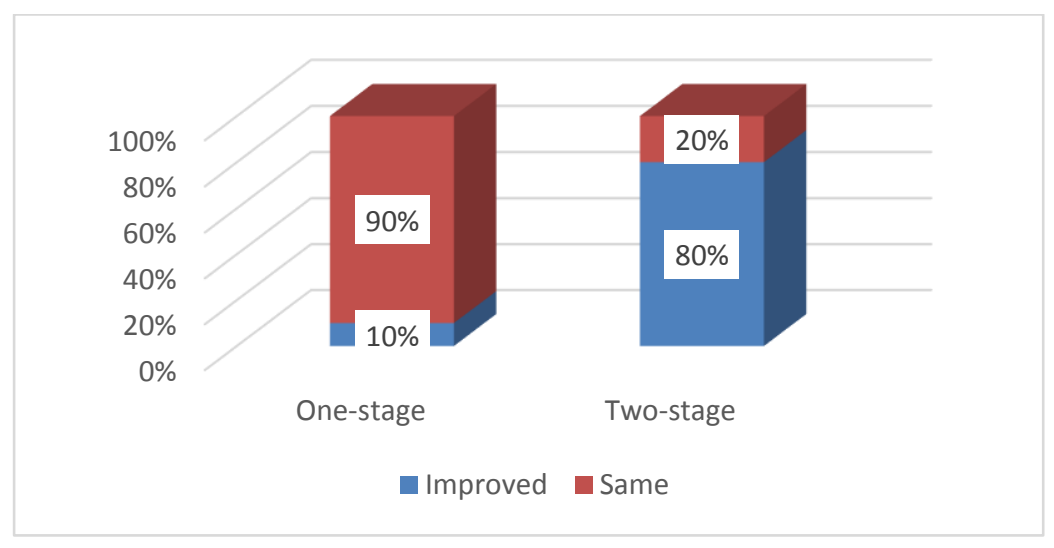

Diagram 2: Change of ROM of knee after management

There was a significant difference between the two study groups with regard to the complications ( $\mathrm{p}$-value $=0.001$ ). The most frequent complication in the one-stage Table 3: Post-operative clinical outcomes. group was PTI (100\% of cases alone), followed by Knee stiffness (30\%) of cases. In the two-stage group, it was the recurrence of infection (30\%), as shown in Table 3.

\begin{tabular}{|c|c|c|c|}
\hline & One-stage & Two-stage & \\
\hline & $\mathrm{N}=10$ & $\mathrm{~N}=10$ & p-value \\
\hline Healing time in month, mean (SD) & $8.6 \pm 2.5$ & $8.4 \pm 1.7$ & 0.945 \\
\hline Median (IQR) & $7.5(5)$ & $9(4)$ & \\
\hline Minimum-Maximum & from $6-12$ & from 6-10 & \\
\hline Range of movement 6 months after healing in degrees, mean (SD) & $83 \pm 32$ & $102 \pm 26.4$ & \\
\hline Median (IQR) & $100(50)$ & $110(30)$ & 0.025 \\
\hline Minimum-Maximum & $20-110$ & $30-120$ & \\
\hline \multicolumn{4}{|l|}{ Complications } \\
\hline Implant failure and refracture & $0(0.0)$ & $1(10.0)$ & 0.001 \\
\hline Knee stiffness & $3(30.0)$ & $1(10.0)$ & \\
\hline Prominent screw & $0(0.0)$ & $1(10.0)$ & \\
\hline PTI & $10(100.0)$ & $0(0.0)$ & \\
\hline Shortening & $2(20.0)$ & $0(0.0)$ & \\
\hline Foot drop & $1(10.0)$ & $0(0.0)$ & \\
\hline Recurrence of infection & $0(0.0)$ & $3(30.0)$ & \\
\hline \multicolumn{4}{|l|}{ Unexpected surgeries } \\
\hline Revision of fixation & $0(0.0)$ & $2(20.0)$ & 0.101 \\
\hline Bone graft & $0(0.0)$ & $2(20.0)$ & \\
\hline Quadriplasty & $3(30.0)$ & $2(20.0)$ & \\
\hline Removal of screw & $0(0.0)$ & $1(10.0)$ & \\
\hline Tendon transfer & $1(10.0)$ & $0(0.0)$ & \\
\hline
\end{tabular}


There was no significant difference between the two study groups as regard to the unexpected surgeries ( $\mathrm{p}$-value $=0.101)$. The most frequent surgery in the one-stage

\section{Case Presentation:}
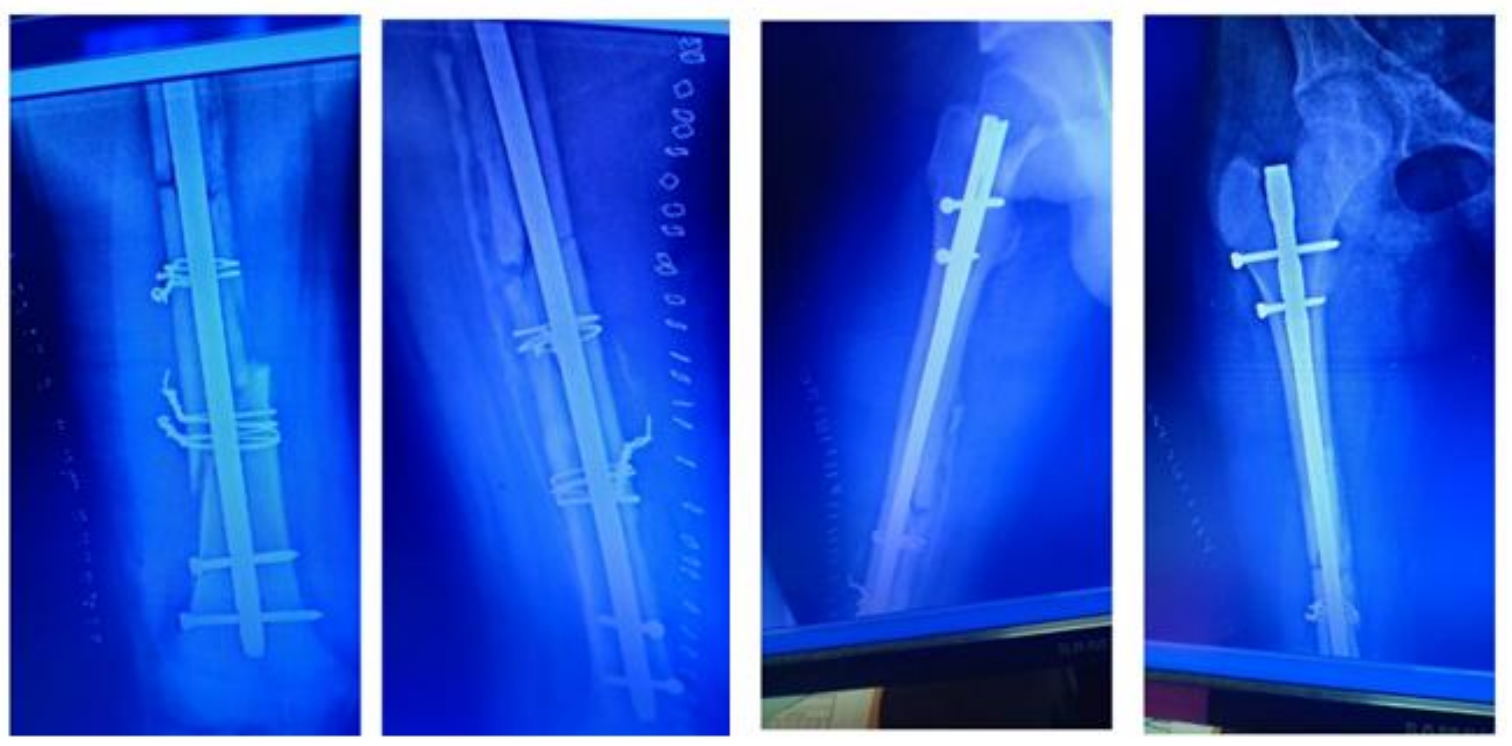

Nail was removed, debridement carried out, then rush pin and cement with antibiotic was inserted until infection was healed.
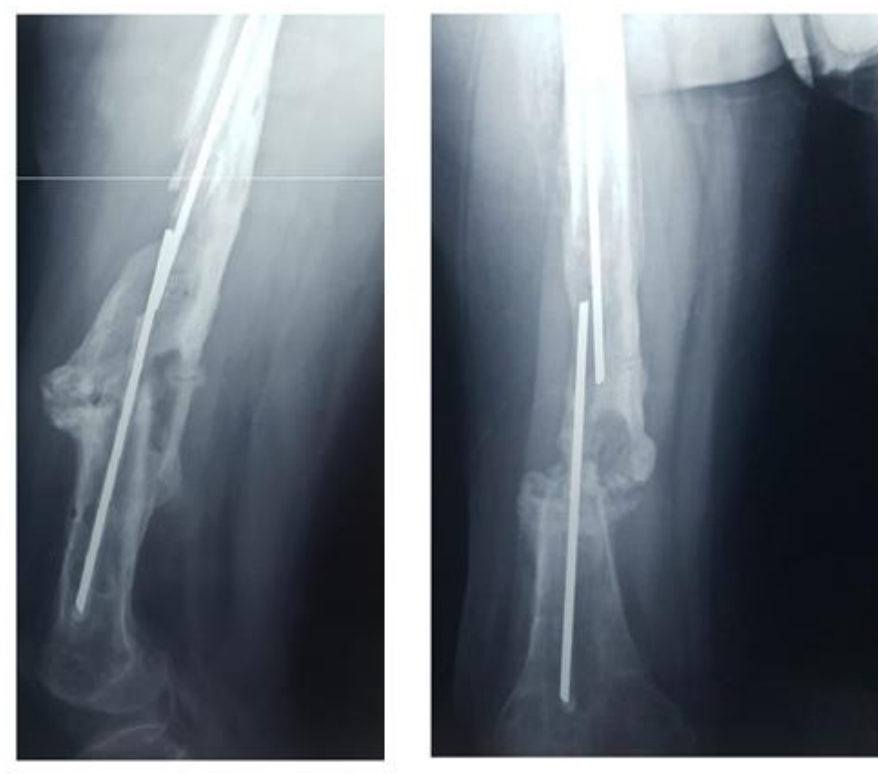

Two months later, infection was healed group was Quadriplasty (30\%). In the twostage group, it was Quadriplasty (20\%), Bone graft $(20 \%) \&$ revision of fixation $(20 \%)$ of cases, as shown in Table 3. 

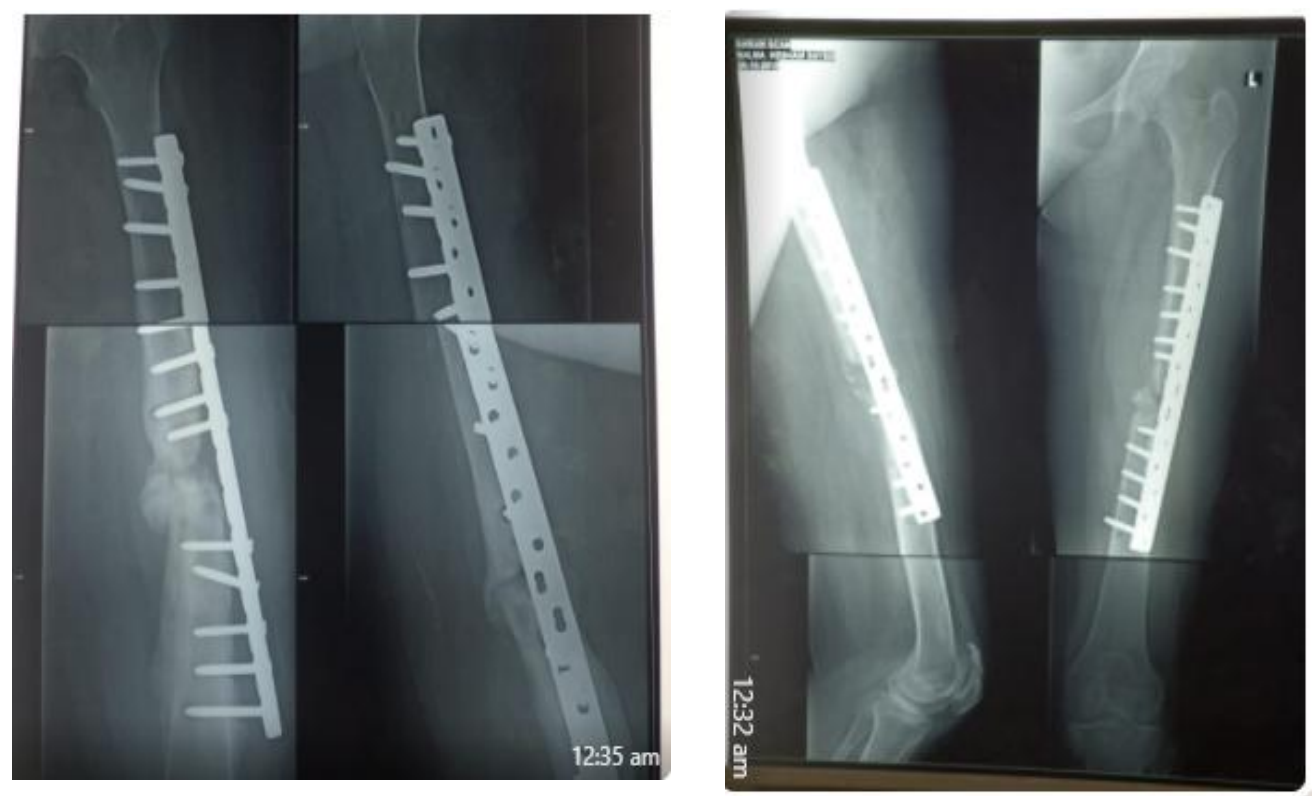

After 9 months of non-union

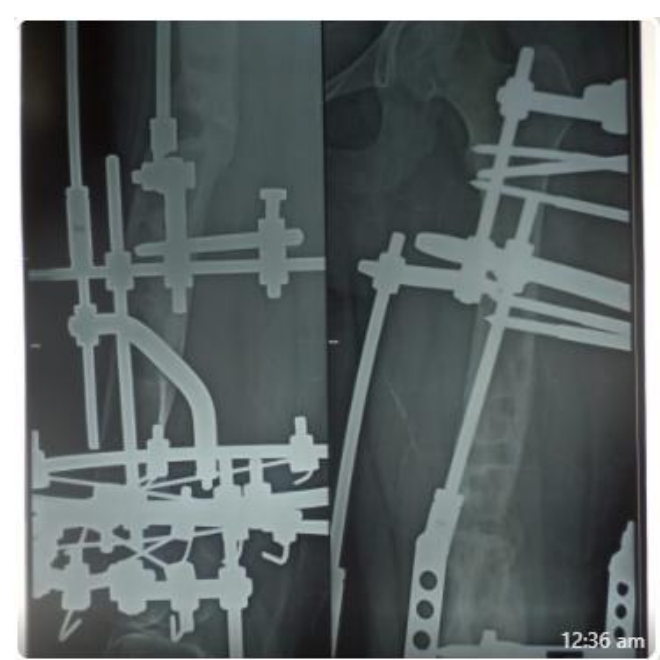

After one stage protocol

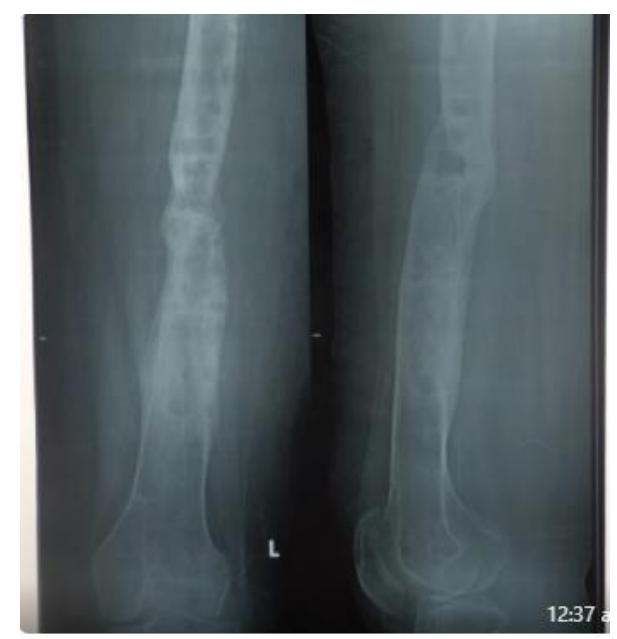

After removal of ilizarov

Figure 2: One-stage protocol case 1: After 9 months of non-union

\section{DISCUSSION:}

The treatment goal for infected nonunited fractured femur is to eradicate the infection, achieve bone healing, and improve the functional result ${ }^{[8]}$. The treatment principles included debridement, fracture stabilization, soft tissue reconstruction, and antibiotic treatment. Stable fixation of the fractures is mandatory for the bone union. There are many available therapies, particularly for large defects, but a two-stage induced membrane technique pioneered by Masquelet and colleagues has recently received extensive attention ${ }^{[9]}$.

The principal method of fixation of the femur after debridement is by external fixation, but this method is cumbersome and associated with many complications as pintract infection and knee extension contracture $^{[8]}$. Many researchers who use 
the Ilizarov technique have tried to shorten the duration of frame application to reduce patient discomfort and avoid the complications of long-time external fixation $[8,10]$.

The results of the current study showed that the mean healing time was $8.6 \pm 2.5$ and $8.4 \pm 1.7$ months for the one-stage group \& the two-stage group, respectively. A significant difference with regard to ROM of the knee 6-months after healing could be detected. The median (IQR) ROM of the knee was 100 (50) and 110 (30) degrees for the one-stage group \& the two-stage group, respectively. The change in ROM before and after management was significant between the two study groups. The ROM was the same in $90 \% \& 10 \%$ for the onestage group \& the two-stage group, respectively. There is a clinical relevance of this result implicating the better ROM in the two-stage protocol. Also, there was a significant difference with regard to the complications. The most frequent complication in the one-stage group was PTI. In the two-stage group, it was the recurrence of infection. The most frequent surgery in the one-stage group was quadriplasty. In the two-stage group, it was quadriplasty, bone graft, and revision of surgery.

The cure of infection is the basis for any definitive treatment of the non-union. In metaphyseal, non-union compression alone is mostly sufficient to achieve bridging. In diaphyseal infected non-unions, a hypertrophic non-union site is rare. Frequently, an extensive resection of dead bone is necessary to eliminate infection, followed by a complex reconstruction of the bone. Achieving stability after bone resection is one of the most important components of the treatment as it allows soft-tissue healing, bone bridging, and neoangiogenesis with the delivery of antibiotics into the fracture site. Generally, temporary stabilization is performed with an external fixator. This allows bridging the site of infection without touching the infected focus and minimizing the chance of reinfection $^{[11]}$. Once the local infection is eradicated, prolonged stabilization must be maintained until the non-union site is bridged with callus. This can be a timeconsuming affair, lasting many months. External fixation remains the treatment of choice in most centers ${ }^{[11]}$.

A unilateral fixator is less bulky than a ring fixator and may give better access to plastic surgery. A ring fixator, according to Ilizarov, allows successive angular corrections during the application as it provides excellent angular and rotational stability and allows early weight-bearing. The Ilizarov method is an essential technique in the management of infected non-union. To combine early weight-bearing with minimal inconvenience for the patient, surgeons have considered internal fixation after resection of infected non-union. This can be performed acutely in the same operation as the debridement or as a second stage after a period of external fixation and antibiotic therapy ${ }^{[11]}$.

Klemm 2012 tested the use of interlocking nails after a radical debridement, mainly local antibiotic treatment versus external fixation. That method was not as safe as external fixation $^{[12]}$. Some research papers compared Ilizarov fixation alone with a fixator exchanged to an interlocking nail as a secondary procedure. Both groups had comparable results, but the patients with a change to an intramedullary (IM) nail experienced fewer restrictions [13]. Early conversion to IM nailing may be more costeffective than completing the treatment with an external device ${ }^{[14]}$. A $27 \%$ risk for reintervention due to remaining problems of non-union or recurrence of infection is reported. This may be considered acceptable in view of the complex problem and the lesser morbidity compared to external 
fixation devices ${ }^{[15]}$. The presence of a nail after successful eradication and the bone union will reduce the risk of refracture. More recently, IM nails coated with antibiotic-loaded polymethylmethacrylate (PMMA) cement have been inserted after radical debridement. However, there is still a substantial risk of recurrence of infection $(25-40 \%)$ and the need for further surgery ${ }^{[16]}$.

One systematic review and metaanalysis was carried out by Yin et al. (2015) concluded that Ilizarov methods may be a good choice for the treatment of infected non-union of tibia and femur ${ }^{[17]}$.

In a study by Rashed et al. (2016), the infection could be controlled in $11(91.7 \%)$ cases by single-stage procedure with the use of antibiotic-loaded bone cement and could not be controlled in one $(8.3 \%)$ case. They concluded that this simple procedure is encouraging, cost-effective, and less cumbersome $^{[18]}$. However, placement of intramedullary antibiotic bead chains in the medullary canal is cumbersome for placement of external fixators. It provides no mechanical support for the fracture and cannot fill up the dead space completely ${ }^{[19]}$. Furthermore, the in-growth of granulation tissue between the beads makes it difficult to remove the beads ${ }^{[20]}$. Some authors began using self-made antibiotic-impregnated cement rods to treat infection of tibial fractures after nailing, and good results were obtained $^{[21,}{ }^{22]}$. In comparison with antibiotic-impregnated cement beads, cement rods have enough intensity and proper diameter and can be easily inserted to fill up nearly all of the dead space ${ }^{[20]}$.

Thonse and Conway (2007) have studied 20 cases of infected non-union with a bone defect. They had achieved union by the primary use of antibiotic-impregnated cement nail in two cases with bone defect, with the remaining cases requiring a secondary procedure. They reported infection control in $95 \%$ of their cases ${ }^{[23]}$.
Also, Chen et al. (2003) and Babhulkar and Pande (2005) achieved 100\% union in their series by following a two-stage procedure. There were no patients with persistent infection. Shahcheraghi and Bayatpoor (1994) also found $100 \%$ union in their series, especially in patients treated with intramedullary nailing and bone grafting. $\mathrm{He}$ also encountered $33 \%$ persistent infection in his series ${ }^{[24-26]}$.

\section{Conclusion:}

In conclusion, this study showed that the two-stage management of femoral fracture septic non-union gives better range of motion of knee, minimizes the period of immobilization, better psychological status of patient but had a higher incidence of recurrence of infection, metal failure, and non-union.

\section{REFERENCES:}

1. Seenappa, H. K., Shukla, M. K., \& Narasimhaiah, M. .Management of complex long bone nonunions using limb reconstruction system. Indian journal of orthopaedics, 2013: 47 (6), 602-607.

2. Seebach, E., \& Kubatzky, K. F. Chronic Implant-Related Bone Infections-Can Immune Modulation be a Therapeutic Strategy?. Frontiers in immunology, 2019:10, 1724.

3. Motsitsi N S. Management of infected nonunion of long bones: Injury 2008; 39(2):155-60.

4. Michael E and Millerm D, Jesser ADA, et al. Treatment of Infected Non-union and Delayed Union of femur Fractures With Locking Intramedullary Nails. Clinical Orthopaedics and Related Research 1989; 245.

5. Shahid M, Hussain A, Bridgeman $\mathrm{Ph}$, et al. Clinical Outcomes of the Ilizarov Method After an Infected Tibial Non Union Arch Trauma Res. 2013; 2(2).

6. Patil S and Montgomery R. Management of complex tibial and femoral non-union using the Ilizarov technique, and its cost 
implications. J Bone Joint Surg Br. 2006; 88(7): 928-32.

7. Leduc $\mathrm{S}$, William $\mathrm{M}$ and Ricci MD. TwoStage Protocol: Treatment of Non-union After Treatment of Infection J Orthop Trauma 2007; 21(7):505-6.

8. Emara, K., Ghafar, K.E., Diab, R.A., \& Kersh, M.A. One stage versus two stages strategies in the management of femoral shaft infected non union. MOJ Sports Med. 2017;1(2):24-26.

9. Micev AJ, Kalainov DM, Soneru AP. Masquelet technique for treatment of segmental bone loss in the upper extremity. J Hand Surg. Am. 2015;40(3):593-598.

10. $\mathrm{Wu} \mathrm{CC}$, Chen WJ. Tibial lengthening: technique for speedy lengthening by external fixation and secondary internal fixation. J Trauma. 2003;54(6):1159-1165.

11. Lammens, J. et al. Infected non-union. In S. Kates, O. Borens (Eds.), Principles of Orthopedic Infection Management. AO Foundation, Davos Platz, Switzerland. 2016;167-188.

12. Klemm KW. Treatment of infected pseudarthrosis of the femur and tibia with an interlocking nail. Clin Orthop Relat Res. 2012; 174-181.

13. Emara KM, Allam MF. Ilizarov external fixation and then nailing in management of infected nonunions of the tibial shaft. $\mathrm{J}$ Trauma. 2008; 65(3):685-691.

14. Emara KM, Diab RA, Ghafar KA. Cost of external fixation vs external fixation then nailing in bone infection. World J Orthop. 2015; 6(1):145-149.

15. Thonse R, Conway JD. Antibiotic cementcoated nails for the treatment of infected non-unions and segmental bone defects. J Bone Joint Surg Am. 2008; 90(4):163-174.

16. Conway J, Mansour J, Kotze $\mathrm{K}$, et al. Antibiotic cement-coated rods: an effective treatment for infected long bones and prosthetic joint non-unions. Bone Joint $\mathrm{J}$. 2014; 96-B(10):1349-1354.

17. Yin $\mathrm{P}, \mathrm{Ji} \mathrm{Q}, \mathrm{Li} \mathrm{T}$, et al. A Systematic Review and Meta-Analysis of Ilizarov Methods in the Treatment of Infected Nonunion of Tibia and Femur. PLoS ONE 2015; 10(11):e0141973.

18. Rashed RE, Nigm MA, Elaziz MA, et al. Management of infected nonunions by using antibiotic-impregnated bone cement. Egypt Orthop J 2016;51:26-34

19. Klemm KW. Antibiotic bead chains. Clin Orthop Relat Res 1993; 295:63-76.

20. Galfat DR, Agnihotri A, Bansal A. Management of infected non union of long bones with antibiotic impregnated cement nail. Natl J Med Dental Res 2013; 1:25-32.

21. Paley D, Herzenberg JE. Intramedullary infections treated with antibiotic cement rods: preliminary results in nine cases. $\mathrm{J}$ Orthop Trauma 2002; 16:723-729.

22. Ohtsuka H, Yokomaya K, Higashi K, et al. Use of antibiotic-impregnated bone cement nail to prevent septic nonunion after open tibial fractures. J Trauma 2002; 52:364366.

23. Thonse R, Conway J. Antibiotic cementcoated interlocking nail for the treatment of infected nonunions and segmental bone defects. J Orthop Trauma 2007; 21:258268.

24. Chen CE, Ko JY, Wang JW. Infection after intramedullary nailing of the femur. $\mathbf{J}$ Orthop Trauma 2003; 55:338-344.

25. Babhulkar S, Pande K. Nonunion of the diaphysis of long bones. Clin Orthop Relat Res 2005; 431:50-56.

26. Shahcheraghi GH, Bayatpoor A. Infected tibial nonunion. Can J Surg 1994; 37:209213. 


\section{مقارنة بين بروتوكول المرحلة الواحدة مقابل بروتوكول المرحلتين في علاج الكسر الغير ملتئم المصاب بالعدوى لعظمة الفخذ برول}

خالد محمد عمارة*، رامي احمد دياب*، محمد احمد القرش*، ايمن فتحي منير*، احمد محمود بار الدين***

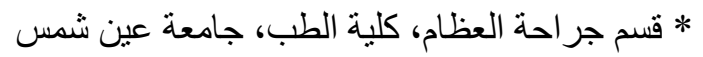

|*صائي جر احة العظام، مستشفى إمبابة العام

المقدمة: نتيجة لارتفاع معدل الكسور المعقدة الغير ملتئمة. تحتاج الكسور المصابة بالعدوي الغير ملتئمة إلى مزيد من البحث عن أفضل طريقة للعلاج.

هدف الدراسة: هدفت الدراسة إلى المقارنة بين نتائج بروتوكول العلاج ذو المرحلة الواحدة (بتطبيق تقنية التثبيت

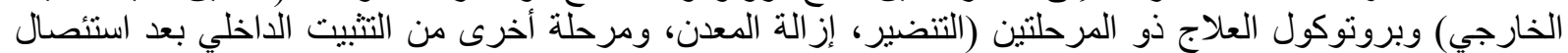

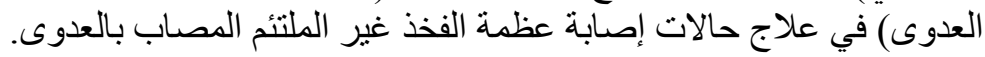

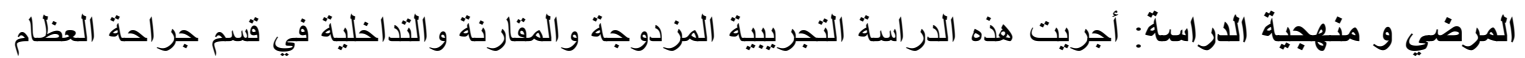

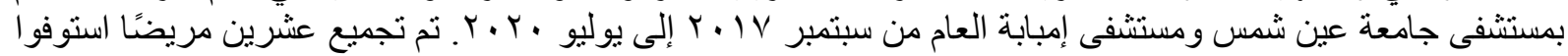

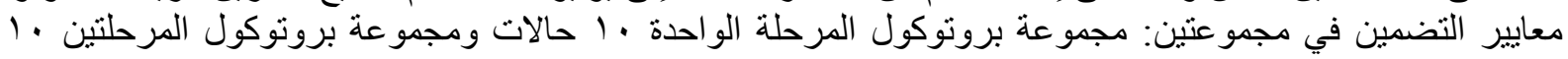
حالات.

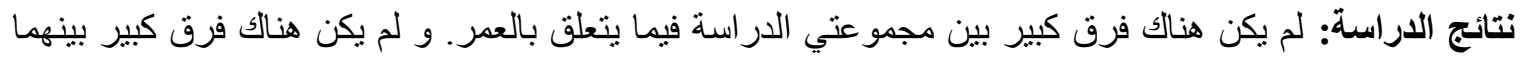

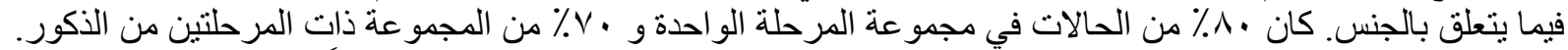

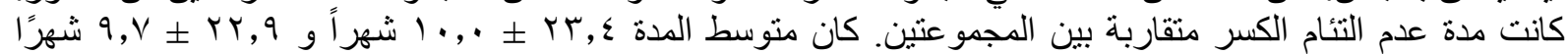

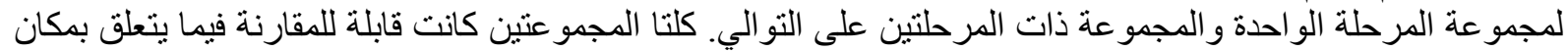

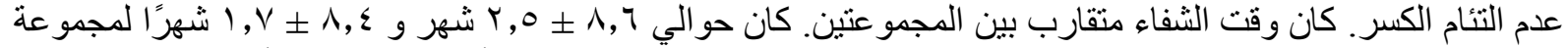

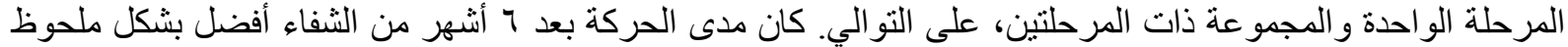

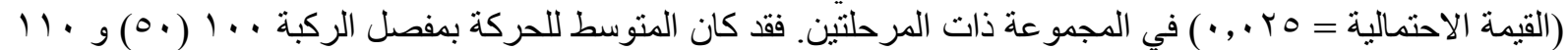

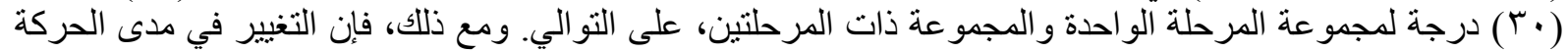

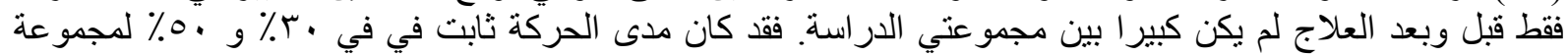

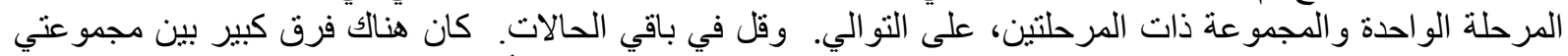

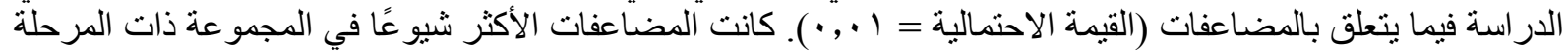

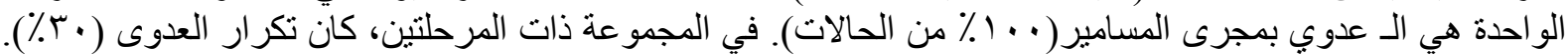

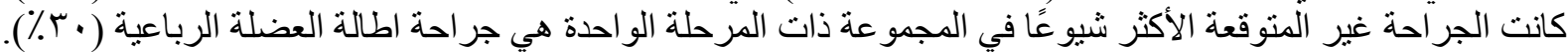

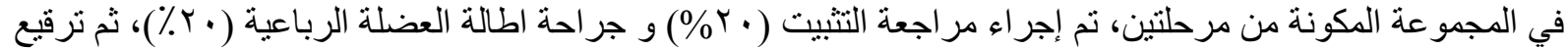

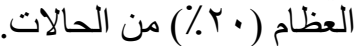

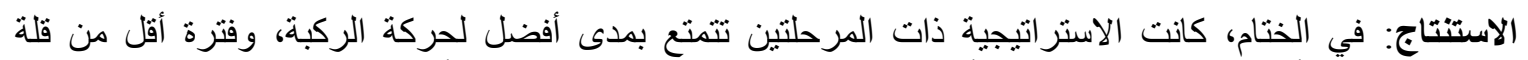

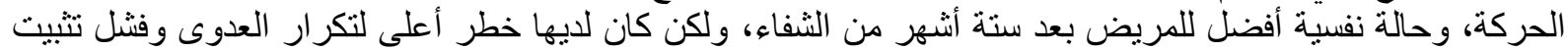

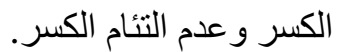

